\title{
Eagle Minds: Selected Correspondence of Istvan Anhalt and George Rochberg
} (1961-2005). Edited by Alan M. Gillmor. Waterloo, Ont.: Wilfrid Laurier University Press, 2007. 474 pp. , facsimiles. ISBN 978-1-55458-018-7 \$85.00 (cloth) ${ }^{1}$

Collected letters have long been considered a valuable source for providing insight into the character, working methods, and motivation of a composer. More rare is a collection such as Eagle Minds, which traces exchanges between two composers over an extended period of time. The volume offers forty-four years of correspondence between two leading musical figures from the U.S. and Canada: George Rochberg and Istvan Anhalt.

Editor Alan Gillmor, in his thorough introduction, explains the genesis, scope, and editorial choices made in the book, including why personal aspects of the letters were excised. He also provides valuable analysis that stems from his intimate association with the materials over many years as well as his personal contact with both men. Together these materials prove insightful, as they guide the reader through the various stages of the correspondence and highlight recurring themes. There is no deliberate offering of biography, as the letters provide it inherently and references to the composers' own writings entice the reader to these sources as well. Gillmor's decision to "over-document" is well-handled, with succinct explanations for many of the more obscure or esoteric references found in the text.

The sagacity of Gillmor's division of the correspondence into five categories is borne out by the letters themselves. It is as though the composers arranged stages of their correspondence with each other. Thus, the progression through A New Friendship (19611964), Musical Composition (1965-1976), The Aesthetics of Survival and Alternative Voices (1981-1985), Politics, Religion, and Society (1986-2000), and Envoi (2001-2005) is logical and provides the reader with a tool for following the evolving lines of Anhalt's and Rochberg's thinking.

Perhaps the deepest insight Gillmor offers is his analysis of the fundamental differences between Anhalt's and Rochberg's styles, both musical and written. In providing the generalizations ( "clichés," as Gillmor himself admits) of Rochberg as the "romantic" and Anhalt as the "classical" protagonists, they nonetheless ring true.

Gillmor's admirable writing style is illustrated by his comment about influences:

We are always curious to know something of a composer's musical and literary tastes, for such knowledge acts like a mirror of the mind, helping us to situate creative figures within a finite number of aesthetic frameworks, thereby facilitating a deeper understanding of the changing profile of their work as it responds to the expansion and layering of experience.” (xxvii)

\footnotetext{
${ }^{1}$ (C) 2009 The author and the Canadian Association of Music Libraries, Archives, and Documentation Centres / L'auteur et l'Association canadienne des bibliothèques, archives et centres de documentation musicaux.
} 
As for the letters themselves, they are delightful and moving, intense and brilliant. These correspondents are "eagle minds" (a reference to Rochberg quoting Yeats (31 March 1994)), two individuals who were exceptionally well-read and alert to their cultural surroundings and identities. As composers, they engage in extensive self-criticism, offer positive feedback to each other, and occasionally confess compositional difficulties. Note, for example, Rochberg's critique of Anhalt's paper, "Music: Mode of Human Communication" - "I'm not sure I agree with the rationale of your approach but I see its logic” (25 March 1962), or Anhalt’s praise of Rochberg's Magic Theater - “A wonderfully beautiful piece... it speaks to one as if you have written it in the course of a single inhaling" (23 January 1966). Occasional outbursts show personal viewpoints, and are even occasionally humorous - Anhalt, about reviewers: "Let the critics jump in the lake” (20 November 1982) - Rochberg, about writing tonal music: "It's like breathing clean air again” (26 June 1971). Though neither composer shows a penchant for engaging in criticism of other composers, there are many nuggets of commentary: Rochberg - "In truth what I'm saying is that you are infinitely superior to Cage" (4 August 1967); Anhalt - "Ligeti’s / Requiem / (it is a gimmicky piece, not better than Penderecki)" (30 September 1970). Comments such as these are typically more analytical than judgmental, and there is a sense that both respect the work of other contemporary composers. The lens of respect through which they perceive the art of music, and that they accord to their compositional and performing colleagues, is naturally extended to each other. Permeating every letter is the palpable respect between friends who have grown to love each other at all times. There is an openness and vulnerability that exudes throughout, and no unkind or hurtful word - it is a testimony to the dying art of letter writing.

It is somewhat disappointing that the letters have been edited for content - as Gillmor admits, he has removed personal material that "had little or no bearing on the subjects' creative lives." Certainly the reader is left with ample information to understand the deeper thinking and creative processes of both composers, so the intent of this book is not undermined, and it retains considerable scholarly "weight." However, the reader is left not knowing what is missing, and therefore in need of trusting the editor's judgment. When one reads Schubert's letters, for example, it may or may not help scholarly writers to read of his begging for money from his friends, but it certainly provides personal glimpses that an analyst might be able to use. It may be that the excision of personal comment narrows the scope of future scholarship for these two important musical figures. Nevertheless, Anhalt and Rochberg emerge as substantive, both personally and musically. This strong and gratifying book - really the collaboration of three eagle minds - is a satisfying blend of personality and scholarship.

\section{Jon Gonder}

School of the Arts

State University of New York at Geneseo 